\title{
O PARADOXO DO ISOLAMENTO NA PANDEMIA SEGUNDO O POVO INDÍGENA SATERÉ-MAWÉ/AM
}

\author{
THE PANDEMIC ISOLATION PARADOX ACCORDING TO \\ THE INDIGENOUS PEOPLE SATERÉ-MAWÉ/AM
}

\section{LA PARADOJA DEL AISLAMIENTO EN LA PANDEMIA SEGÚN LOS INDÍGENAS SATERÉ-MAWÉ/AM}

\author{
Bader Burihan Sawaia ${ }^{1}$, Renan Albuquerque ${ }^{2}$ \\ e Flávia Roberta Busarello ${ }^{1}$ \\ ${ }^{1}$ Pontifícia Universidade Católica de São Paulo, São Paulo/SP, Brasil \\ ${ }^{2}$ Universidade Federal do Amazonas, Manaus/AM, Brasil
}

\begin{abstract}
RESUMO: O artigo teve como meta analisar e aprofundar interpretações acerca da relação entre desigualdade e pandemia em dimensão psicossocial, com foco no isolamento enquanto questão emblemática para indígenas SateréMawé, do Amazonas, e nos afetos como categoria analítica. Buscamos referencial teórico em Spinoza e Vigotski para a concepção ético-política dos afetos. Inferências descritas tiveram base em documentos públicos e etnografia continuada. Observamos afetos vivenciados diante de uma situação de isolamento territorial dos étnicos da TI Andirá-Marau, que remetem ao paradoxo dessa estratégia recomendada aos povos indígenas. Concluímos que a pandemia, para sociedades nativas, tem ativado medos históricos, situados a partir de violências do passado, mas também fomentou sabedorias salvadoras de vida.
\end{abstract}

PALAVRAS-CHAVE: Psicologia social; Povos indígenas; Estresse psicológico; Afetividade; Amazônia.

RESUMEN: El artículo tuvo como objetivo analizar y profundizar las interpretaciones sobre la relación entre la desigualdad y la pandemia en una dimensión psicosocial, enfocándose en el aislamiento como un tema emblemático para los indígenas Sateré-Mawé, de Amazonas, y en los afectos como categoría analítica. Buscamos referencias teóricas en Spinoza y Vigotski para la concepción ético-política de los afectos. Las inferencias interpretativas descritas se basaron en documentos públicos y etnografía continua. Observamos afectos experimentados ante una situación de aislamiento territorial de los grupos étnicos del territorio indígena Andirá-Marau, que se refieren a la paradoja de esta estrategia recomendada a los pueblos indígenas. Concluimos que la pandemia, para las sociedades nativas, ha provocado temores históricos, basados en la violencia pasada, pero también ha fomentado la sabiduría para salvar vidas.

PALABRAS CLAVE: Psicología social; Pueblos indígenas; Estrés psicológico; Afectividad; Amazonas.

ABSTRACT: The article aimed to analyze and to deepen interpretations about the relation between inequality and pandemic in a psychosocial dimension. It focused on isolation as an emblematic issue for the Sateré-Mawé indigenous people of the state of Amazonas, Brazil, as well as on affection as an analytical category. We sought the Theoretical Reference in Spinoza and Vigotski for an ethical-political conception of affections and interpretive inferences were based on public documents and continued ethnography. We observed affections experienced in the face of a situation of territorial isolation of the ethnic Andirá-Marau Indigenous Territory, which leads to the paradox of this strategy being recommended to indigenous peoples. We conclude that, for native societies, the pandemic has activated historical fears, which are situated from violence of the past. However, it has also contributed to the wisdom that saves lives in the pandemic.

KEYWORDS: Social psychology; Indigenous peoples; Psychological stress; Affectivity; Amazon. 


\section{Introdução: indígenas e a Covid-19}

Muito se está escrevendo sobre o agravamento da pandemia por causa da desigualdade social estrutural no Brasil. Dados ponderativos ${ }^{1}$ demonstram como o surto foi empurrando a pobreza para a linha de frente dos fatores de correlação da letalidade do coronavírus. Dentre as comorbidades agregadas ao espalhamento do $S A R S-C o V$-2, destaca-se a usurpação do direito ao isolamento, única forma de prevenção até o momento com eficácia comprovada.

A desigualdade social está atrelada diretamente à adesão ao isolamento, definindo quem pode e quem não pode ter esse direito, instaurando um dilema insolúvel entre a adesão ao isolamento pelo medo da morte por contaminação e a recusa pelo medo da fome que ele ocasiona. Sem contar a covariância entre desigualdades sociais, política de produção de ignorância e biopolítica do governo federal para povos vulneráveis (Jacobi, 2020; Sousa, Gonçalves, \& Cruz, 2020, Travassos et al, 2020).

Nesse caldeirão de comorbidades, a precarização sanitária e econômica ganhou traços contundentes na região norte do país. Manaus/AM, Belém/PA, Macapá/AP e Porto Velho/RO foram as cidades-pólo amazônicas mais afetadas. Casos de infecção e morte por coronavírus, apesar de subnotificados em uma ordem até oito vezes menor do que realmente são, concentram-se prioritariamente em interiores amazônicos (Ferrante \& Fearnside, 2020).

A dimensão caótica da falta de planejamento agravou a situação. De 7 de abril a 3 de junho, declarações públicas de políticos e gestores negacionistas reverberaram na saúde das 25 milhões de pessoas da região amazônica. Proporcionalmente, em um intervalo de 71 dias, contando-se esse período e mais os 15 dias anteriores, a taxa média de ocupação de leitos clínicos e de UTI em Manaus e Belém subiu de 68\% e 58\% (em fins de março), respectivamente, para picos de $96 \%$ e 92\% (na segunda e terceira semanas de abril), mantendo-se na média de $80 \%$ em todo o mês de maio e junho (Universidade Federal do Amazonas - Instituto de Ciências Exatas, 2020; O Globo, 2020).

Os números embasam o cenário de crise humanitária para o qual chamamos atenção. Uma crise que reatualizou e rememorizou um tipo de morte conhecida de amazônidas, totalmente vinculada à desigualdade social e à histórica inclusão perversa decorrente. Situação que se somou às comorbidades já instauradas na região, agudizadas com a pandemia.

Territórios amazônicos, em boa medida, ao abrigarem sociedades com modos de vida próprios, guardam em si tipos de particularidades controversas, porque, como notamos, a pandemia na região só não se alastrou ainda mais em função dessa complexidade multidimensional de deslocamento presente no território. Pois ao mesmo tempo em que uma pessoa infectada pode morrer pela demora em se chegar a um centro urbano, infectados/as com maior dificuldade de locomoção espalham com menor velocidade a doença para interiores (Albuquerque, 2020). Ou seja, existem conjunturas infra-estruturais que, em si mesmas, concorreram para salvar pessoas em meio à situação. Mas elas não bastaram.

A sabedoria ancestral salvou e ainda salva amazônidas em meio a essa conjuntura grave. Por iniciativa própria, importante parcela dos povos indígenas que vivem na mesorregião do Baixo Amazonas/AM, na Amazônia Central, onde índices de infecção por Covid-19 estiveram entre os seis maiores do país para espaços periféricos não urbanos do Brasil (Atlas/ODS, 2020), planejou e executou um modelo de isolamento social pautado 
em estratégias ancestrais de defesa contra o perigo. Um dos povos que impulsionaram a atividade foi a sociedade nativa dos Sateré-Mawé, juntamente com demais grupos indígenas do Brasil. Como relata um membro da etnia Tuyuka, do Alto Rio Negro, a ação retomou atos tradicionais do passado ameríndio.

Diariamente [no passado], o grupo de sábios fumando os seus cigarros conversava sobre o que tinha visto em seus sonhos, que fórmula de proteção havia criado em sua meditação noturna. Cada sábio apresentava alguma solução. Com os seus sensos apurados, desviavam a rota das doenças para não chegarem até nós (Rezende, março de 2020, p. 125.).

Segundo o conselho geral da tribo Sateré-Mawé, a etnia constitui-se como a maior em termos populacionais da região, com 13,5 mil pessoas. São donos da terra indígena Andirá-Marau, de 789 mil hectares, homologada pelo Decreto no 93.069 - 07/08/1986, na divisa do Amazonas com o Pará. Os Sateré-Mawé se organizam via clãs hierárquicos de poder político, construídos com base no sistema ancestral de parentesco, referenciado por conjunto totêmico composto de 16 animais e duas plantas, sendo uma mítica ${ }^{2}$. Vivem na mesorregião do Baixo Amazonas/AM, como destacamos.

O presente texto elegeu esse povo para colaborar com uma importante busca - que todas as ciências estão fazendo, atualmente - de respostas e orientações para ações de enfrentamento não apenas à pandemia singularmente, mas de entendimento amplo acerca de fator que aumenta o risco de contágio e letalidade do coronavírus: a desigualdade social. Foi enfocada, assim, especificamente, a questão do isolamento social, que é a única possibilidade presente de controle da pandemia na ausência da vacina e medicamentos.

A escolha se deveu, primeiro, ao clamor de Silvia Lane para que a Psicologia corrigisse o erro histórico de se voltar apenas à população branca e urbana, desconsiderando povos originários e tradicionais em geral. Assim pensando, chamamos atenção para o fato de que a grande mestra da psicologia social brasileira fez pesquisa em 2005 com os Xavante ${ }^{3}$, demonstrando erros conceituais sobre a acepção da categoria primitivo, afirmando a potência do conhecimento de povos originários para a psicologia e a importância de se buscar diálogos de forma simétrica.

Enfocamos o lugar emblemático que povos indígenas ocupam na sociedade brasileira, marcado por extrema desigualdade social colonialista, resistindo sem perder a potência de vida, apesar de subsumidos pelo poder público. De modo que, conhecendo impactos de doenças de karaiwáa (gente branca), organizaram o fechamento de Terras Indígenas (TIs) para se protegerem do vírus, o que foi estratégico em razão da dimensão da pandemia da Covid-19 em territórios amazônicos.

A grande pergunta do texto foi: como, apesar do descaso do Estado, vivendo em território de extrema pobreza e carregando em seus corpos a memória de genocídios, inclusive por outras doenças infecto-contagiosas de gente branca, uma comunidade indígena continua resistindo a desmandos e bloqueios ao seu direito de existir com dignidade, usando uma estratégia ancestral, o isolamento, para salvar comunidades em confronto direto com a política de morte dominante?

O lugar analítico foi o da psicologia sócio-histórica, que coloca a incumbência de se verificar a relação entre pandemia, desigualdade e isolamento social em dimensões subjetivas, igualmente singulares e coletivas, para compreender o profundo drama humano 
desenrolado nesse contexto. Entendemos que a omissão dessa dimensão psicossocial reforça o tratamento de rebanho dos/as que sofrem a inclusão perversa, reduzindo-os/as a análises estatísticas, desconsiderando sutilezas emocionais, que muitos/as pensam ser privilégio dos/as que ultrapassaram as necessidades do estômago.

A partir das reflexões, elegemos o afeto como categoria analítica central e fomos buscar na Teoria dos Afetos, de Lev Vigotski, e seu filósofo de referência, Baruch Spinoza, concepção sócio-histórica da afetividade, que retira as pessoas do psiquismo e lança olhares sobre conflitos sociais vividos.

\section{Enfoque teórico: os afetos}

Vigotski, pesquisador russo do início do século XX da área da educação e da Psicologia, foi um dos responsáveis por introduzir o materialismo histórico-dialético no estudo do psiquismo, visando superar dicotomias que, segundo ele, prejudicavam o desenvolvimento de uma Psicologia capaz de compreender o ser humano na sua totalidade e movimento. Nesse intuito, recorre à filosofia de Spinoza, que, no século XVII, criticava o conhecimento supersticioso produzido por religiões e universidades e as separações entre mente e corpo, razão e emoção, promovidas pelo cartesianismo. O filósofo também criticava a visão pessimista do ser humano de Hobbes e sua defesa de que só o Estado forte é capaz de nos proteger de nós mesmos/as e garantir uma vida em comum.

Spinoza (1677/2013) defende que somos potência de perseverar na existência, de forma autônoma e livre, o que só é possível na relação com outros seres humanos, e que podemos alcançar a felicidade em comum ao aprendermos a conhecer nossos afetos e, principalmente, as causas que os engendram. Afastando-se da ideia de moralidade vigente no século XVII, imprimiu nova orientação à ética, situando-a nos afetos e na capacidade de pensar adequadamente sobre eles, evitando ilusões. Tratou de uma ética encarnada. "Os afetos (affectus) são um determinado tipo de afecções (affectiones) que têm como consequência um aumento ou diminuição do nosso agir" (Vigotski, 2000, citado por Ferreira, 2003, p. 109).

A partir da visão de Spinoza (1677/2013), alegria e tristeza não constituem estados psíquicos. São modos de viver e experimentar. Alegria é afeto que sentimos em bons encontros que aumentam a potência de vida (autonomia). Portanto, corresponde à passagem de uma perfeição menor para uma maior. A tristeza, ao contrário, é sentimento de diminuição da própria potência de existir e agir, representando a impotência em reagir a revezes da vida e da incapacidade de lidar com ideias confusas.

Vigotski traduz essas ideias para a Psicologia, defendendo que afetos não se separam do pensar e do agir e que ninguém pensa, sente e age sem estar emocionado. Também destaca a dimensão sócio-histórica dos afetos, bem como o seu papel de mediadora de experiências. Pelos afetos, o mundo é experimentado, assim como suas contradições, conflitos e ideologias. Afetos demonstram a qualidade da situação social de sujeitos.

Daí o destaque, no presente texto, ao conceito de sofrimento ético-político de Bader Sawaia (2001, pp. 104-105) em referência a afetos mutiladores da vida, que concorrem para sofrimentos surgidos "da situação social de ser tratado/a como inferior, subalterno/a, sem valor, apêndice inútil da sociedade”. Portanto, é sofrimento não experimentado democraticamente, mas exclusivo de quem sofre a inclusão perversa ou a subcidadania. 
Afetos não são simplesmente reações do corpo e da mente a estímulos exteriores, constituem radar ético-político de problemas e dificuldades sociais geradas pelo cruzamento do vírus da desigualdade social com o vírus $S A R S-C o V$-2. São dispositivos políticos, micro maneiras das paixões tristes dominarem a vida social, impedindo humanos de se engajarem e instalando um tipo de passividade civil (Pessanha, 2020). ${ }^{5}$

Spinoza (1677/2014) afirma que regimes autoritários se valem do engano e o disfarçam para produzirem um desejo paradoxal de subserviência, que se acha determinado por medo e esperança. A humanidade é consciente de seu desejo, mas não conhece as causas que a movem a desejar o que deseja. Essa é a tarefa de uma análise dos afetos: compreender as ideias adequadas das motivações (afetos) pelas quais somos determinados/as a crer em certas coisas e participar de certas práticas.

Somos uma configuração concreta de riquezas e misérias singulares, próprias às nossas condições sociais. Por isso, o psiquismo tem que ser analisado como drama (Vigotski, 1986/2000). Em síntese, afetos são fenômenos sociais vividos individualmente, que desencadeiam ações que afetam o corpo social, e constituem a gênese necessária à compreensão da servidão humana, individual e política, tanto quanto a gênese necessária da liberdade humana, individual e política. Por não serem causa, mas efeitos das condições sociais, são fontes confiáveis das emergências humanas provocadas pela pandemia e assim orientadoras da atuação da psicologia social.

Usamos o conceito pelo potencial de se referir a impactos que vão além de econômicos, ambientais e biológicos, abarcando o que, segundo Spinoza (1677/2013), é direito natural de pessoas que perseverarem na vida com autonomia e felicidade. Sobre a questão, Vigotski completa com o direito à imaginação como base da liberdade. Segundo ele, "a imaginação cumpre um papel de libertar o homem [sic, ipsis litteris] da sua condição de vida, das leis da natureza na medida em que possibilita a reconstrução da realidade e o domínio da sua própria evolução” (Vigotski, 2000, citado por Pino, 2006, p. 49). De modo que o imaginário é o que define a condição humana.

Pensar emergências humanas no contexto da pandemia é verificar necessidades psicossociais muitas vezes subsumidas em meio a levantamentos estatísticos e/ou relegadas pela tendência ideológica de reduzir quem sofre desigualdades sociais a somente necessidades de sobrevivência física.

\section{Metodologia: campo de pesquisa e suas relações}

A escolha dos povos Sateré-Mawé para a análise específica da estratégia de isolamento foi feita em razão da autoria do paper trabalhar desde 2012 junto a eles/elas, acompanhando lutas e conquistas em diversos âmbitos, inclusive na tomada de decisão para o isolamento territorial na terra indígena Andirá-Marau. Também, desde 2019, vimos desenvolvendo pesquisa ${ }^{6}$ intitulada "Psicologia social e comunidades tradicionais: em busca da práxis ético-política”, realizada em quatro Estados do Brasil: Rondônia, Amazonas, Santa Catarina e Piauí.

Partindo de visão da Psicologia Crítica, que compreende uma ação norteada para uma transformação social, foi escolhido o método que não reproduzisse a visão eurocêntrica de indivíduo, separando razão/emoção e singular/coletivo. Foi prezada a horizontalidade 
entre pesquisador/a e pesquisado/a, reconhecendo-se diferentes agentes da comunicação no campo do estudo. A multivocalidade das narrativas baseou a pesquisa e o conhecimento nela desenvolvidos via compromisso social.

Para a obtenção de informações adicionais específicas à quarentena, parcela essencial de narrativas e dos informes foi granjeada por redes sociais, mensagens pelo WhatsApp e telefonemas com destacadas lideranças indígenas e demais interlocutores de diversas etnias, que não apenas a Sateré-Mawé. A meta foi verificar como, em termos gerais, informações referentes à pandemia circulam entre as redes de informação de povos originários amazônicos.

Tanto essa coleta, mais geral, entre narrativas e documentos compartilhados entre indígenas, quanto o levantamento específico do isolamento territorial, feito particularmente entre a etnia Sateré-Mawé, respeitaram normas da Organização Mundial da Saúde (OMS) para o isolamento social. Por isso, foi feito uso de tecnologias de comunicação como instrumentos de obtenção de informações.

A escolha de participantes ocorreu por conveniência, considerando-se depoimentos e vivência da realidade acerca da Covid-19, compreendendo que a luta indígena contra o $S A R S-C o V-2$ assolou e ainda assola povos tradicionais da região amazônica e do Brasil. Por isso, optamos por colher depoimentos instigantes de interlocutores/as de outras etnias da região amazônica, sobremaneira aquelas com alto grau de vínculo histórico na região.

Inferências interpretativas descritas tiveram base em documentos públicos e na etnografia continuada que realizamos nos últimos oito anos. Isso permitiu observar afetos vivenciados mesmo diante de uma situação de isolamento territorial da sociedade nativa da TI Andirá-Marau (Tarrant \& Hughes, 2020).

A correlação entre desigualdade social e saúde, comparando-se territórios indígenas e periferias de zonas urbanas, tem sido avaliada desde a redemocratização do estado brasileiro (Jacobi, 2020; Torres, 2020). O ato de recolhimento de povos indígenas em reservas foi pesquisado por Antônio Brand (1993) como confinamento explorador. Renan Albuquerque Rodrigues e Philip Martin Fearnside (2014) exploraram a temática no âmbito da tutela estatal. Nós estudamos o isolamento como questão engendrada no cenário da desigualdade, com rebatimentos na saúde em tempos de pandemia a partir de três tópicos analíticos.

Primeiro, por ser a única medida protetiva não-hospitalar contra a Covid-19 de eficácia reconhecida por autoridades sanitárias. Segundo, por representar estratégia ancestral de indígenas Sateré-Mawé de mitigação contra doenças de gente branca. Terceiro, por ser ato incentivado por boa parte da ala progressista da política indigenista brasileira, apesar de haver tensões históricas do setor.

\section{Resultados e discussão: implicações do paradoxo do isolamento}

O isolamento social, atualmente o único método preventivo de alta eficácia reconhecido pela Organização Mundial da Saúde (OMS) para a mitigação da pandemia do novo coronavírus, tem encontrado obstáculos para sua implantação no país, exigindo alto investimento de dinheiro e tempo do poder público tanto para convencer a população da necessidade da ação quanto para garantir que ela seja feita. Ademais, se por um lado, como afirma a OMS, a eficácia é certa, também há estudos que enfatizam o isolamento como 
impulsionador de estados de sofrimento psíquico (Filgueiras \& Stults-Kolehmainen, 2020; Reger, Stanley, \& Joiner, 2020; Williams, Armitage, Tampe, \& Dienes, 2020).

Para indígenas, no caso Sateré-Mawé, o isolamento é estratégia ancestral para fugir de doenças de gente branca, conforme afirmado anteriormente por Rezende (2020). $\mathrm{Na}$ história do povo, o isolamento contra pestes traz ainda o risco de se agregar a comorbidades relacionais à própria peste, e aqui enfocamos particularmente a Covid-19, por conta da política brasileira que permite invasões a terras nativas por interesses de poder, impedindo a proteção de lugares de refúgio, como faziam ancestrais do continente sul-americano. O isolamento faz parte da sabedoria mítica, mas também da política colonialista de inclusão perversa, que marca tensões da experiência histórica do contato nativo com a gente branca.

A pandemia sublinhou o paradoxo do isolamento vivenciado historicamente por povos indígenas no Brasil a partir das seguintes esferas: o isolamento/proteção frente a ameaças e violências da gente branca e o isolamento/confinamento fruto de políticas de dominação e aprisionamento colonialistas, incluindo-se o isolamento com base no direito à demarcação de terras, que só foi adquirido por legalidade constitucional nos anos 1980, mas até hoje é motivo de disputa pelo agronegócio.

$\mathrm{O}$ isolamento/confinamento é entendido como paradoxal porque modos de vida nativos se formam processualmente e não são estanques. Representam conjuntos próprios de memórias ancoradas à natureza. Ou seja, diferentes nações étnicas, física e simbolicamente, a partir da cultura, sempre marcaram começos e fins de suas terras segundo entroncamentos de rios, pedrais, igapós, curvas de vales, várzeas ou mesmo repetições de árvores de determinada espécie. De distintas maneiras, realizaram ao longo dos tempos registros de seus pertencimentos afetivos e também de pertencimentos de outras nações, quer sejam aliadas ou rivais (Barreto, 2013).

Porém, a partir da redemocratização, a Constituição Federal Brasileira (1988) normatizou por força de lei heranças consanguíneas e cosmológicas e destacou que apenas o Estado estaria apto a reconhecer, decretar e homologar territórios indígenas. Assim, o aparato da lei de um governo não-indígena passava a ser usado para decidir sobre direitos imemoriais de ameríndios/as. O alvo polêmico foi a autodeterminação de espaços afetivos e dominiais, porque, a princípio, a Constituinte estreitou diálogos e deu voz ativa a indígenas, mas o que se viu, no limite, foi uma espécie de reconstrução legalista de abusos que o colonialismo europeu realizou desde 1500 , sobretudo no que concerne a reconhecimento territorial.

Mesmo com o Novo Código Civil (Roberto, 2008), que, em teoria, retirava indígenas da condição de tutela do governo federal, a situação manteve-se controversa por causa da dificuldade de acesso a políticas de inclusão social e assistência. Ao mesmo tempo em que o Estado concebia o direito à territorialidade histórica, desobrigava-se de tornar esse direito sustentável do ponto de vista da cidadania nativa em seus pontos de vista ancestrais (Kopenawa \& Albert, 2015). O recolhimento de povos indígenas em reservas chegou a ser qualificado como confinamento explorador (Brand, 1993), dado se referir a processos ambíguos operados pelo Estado, que geravam sistemática pauperização material e imaterial.

O argumento do confinamento explorador vai ao encontro do que Ailton Krenak (2020) afirma, quando diz que a gente branca está cavando um fosso gigantesco de desigualdades que estão sendo naturalizadas, criando-se uma subumanidade miserável. Com o $S A R S-C o V-2$, ficou evidente o caráter paradoxal dessa relação. A pandemia acentuou a desassistência do Estado Brasileiro, mesmo que o discurso oficial tente mascarar 
essa dura realidade. O isolamento histórico e crônico vivido pelos povos originários no contex to do governo do Brasil tornou-se ainda mais problemático.

O paradoxo isolamento/confinamento e isolamento/direito foi agravado pela Covid-19 também pela situação de distanciamento dos grandes centros para acesso a hospitais e remédios, contabilizado a partir do tempo necessário para viagens de barco, principal transporte da região amazônica, e ainda mais em função de sinuosidades hidrográficas da bacia amazônica. Por exemplo, o tempo médio que uma pessoa, de barco, leva para sair da capital amazonense e chegar até a terra indígena Andirá-Marau, onde vive o povo Sateré-Mawé, a uma distância de $353 \mathrm{~km}$, gira em torno de dois dias em uma viagem direta (sem pausas).

Nesse cenário, o isolamento/proteção pautado no saber ancestral é o único remédio possível de enfrentamento à inclusão perversa decorrente do isolamento/confinamento produzido pelo Estado. No entanto, visto as invasões e o extrativismo predatório praticado pela gente branca, o isolamento/proteção é impossibilitado e dificultado. Portanto, a vida em territórios indígenas desnuda cruamente a submissão da saúde à desigualdade, ao tempo que revela nuances de efeitos diferenciados para povos originários em relação a demais grupos que vivem desigualdades em zonas urbanas. Porém, em suma, embora igualmente perverso e fonte de sofrimento, o isolamento/proteção continua salvando vidas.

O modelo de isolamento/proteção territorial adotado pelos povos Sateré-Mawé começou a ser desenvolvido ainda no início de abril, concomitante ao que fizeram pelo menos 25 etnias em 13 territórios federais. Foram adesões paulatinas e voluntárias, como forma de prevenção à Covid-19. Redes de comunicação organizadas pelas próprias etnias serviram para a atividade, sobretudo a partir do momento em que os povos das terras baixas da América do Sul notaram o avanço crítico do $S A R S-C o V-2$ na Amazônia, em similar período que instituições científicas brasileiras, a saber: Médicos Sem Fronteiras (MSF), conselho editorial da revista Science, Harvard University e Rede Eclesial Pan-Amazônica. Essas entidades denominaram o problema de "crise humanitária".

A decisão de isolamento por parte de indígenas foi uma resposta nativa à crise humanitária criada por um tipo de inclusão perversa promovida pelo mundo da gente branca. A crise expôs sofrimentos engendrados desde a colonização e mostrou que sabedorias ancestrais do ingenium coletivo dos povos originários foram atos decisivos para o enfrentamento à Covid-19, considerando dificuldades de acesso a hospitais e remédios biomédicos a partir do bioma tropical brasileiro.

A realidade factual lhes deu a certeza de que, uma vez infectados pelo novo coronavírus, teriam enormes entraves para o tratamento. Portanto, a possibilidade de mitigação foi direcionada ao isolamento social até o ponto em que se entendeu a ação como estratégia de fortalecimento da potência coletiva de manter a vida. Só que o sentido ancestral de isolamento se chocou com a política colonialista estatal de confinamento.

Cada vez mais o desenvolvimento (questão do garimpo, instalação de hidrelétricas, turismo, lazer e pesca esportiva, etc.) adentra nas terras indígenas e não existe lugar mais seguro, um lugar para ter uma boa saúde. Na contemporaneidade, os nossos locais de nascimentos, as nossas origens, quando chegam algumas epidemias às nossas comunidades se criam certas cosmopolíticas. Desde o começo da história, os povos indígenas foram transformando esta realidade social moderna. (Barreto Bará, 2020, R2 - Linhas Tortas de Pensamento) 
Mesmo a estratégia de fuga para o meio da mata (Leitão, 2020), rumo a lugares onde possuem amplo conhecimento e ligação cosmogônica, hoje sofre impedimentos de diferentes formas, e entre eles citamos desmatamentos e queimadas, bem como invasões de terras por grilagem e à força de armas. Se fosse apenas o perigo do vírus, o isolamento protegeria e tranquilizaria, mas enfrentam o colonialismo e a ganância capitalista como comorbidades. Aí está o paradoxo da medida que expõe a inclusão perversa sofrida desde a colonização, que confinou essas sociedades originárias territorialmente, para excluí-las socialmente.

Interessante constatar que todo um conjunto de pressões sociais, de negação, menosprezo e destruição de saberes tradicionais, não impediu a defesa da vida segundo traços cosmológicos de constituição. Ao contrário, foi justamente a confiança na sabedoria de anciãos e anciãs que ajudou a decisão rápida de fechamento de TIs, ainda em março, enquanto o governo central muito mais confundia a população e hesitava em agir. O saber norteou, como apontamos, pelo menos 25 etnias de 13 territórios do Brasil, que se isolaram territorialmente, apesar das diversidades de cultura e parentesco. Uniram-se em torno de um mesmo útil-comum, a proteção do coletivo.

Em resposta sobre sofrimentos provocados pelo isolamento, disseram ter (a) dúvidas em relação aos atos de autoridades eleitas para lhes dar proteção e (b) medo da política brasileira de ódio e disseminação de ignorância. Essas narrativas nos apontam desconfiança, bem como nos levam a interpretar relações de angústia e desamparo na pandemia, ancoradas pelos adoecimentos e pelas mortes em função do vírus.

Hoje meu grande primo Higino voltou para CASA (sic), onde os Utãpirõporã vieram. Desejo a ele boa viagem e bom retorno à casa. Que leve nossas lembranças e notícias aos nossos parentes (minha mãe, meus avós, minha irmã, meu sobrinho) e primos que estão lá. Boa viagem. (Barreto, junho de 2020, [mídias sociais])

Foi uma honra aprender com você, deve está [sic] na canoa, rindo com seus ancestrais, cultura não é o que branco fala, cultura é o que somos, isso eles nunca saberão... Saudades, sinto a mesma dor quando perdemos Pedro Machado, Erivaldo Piratapuia, que dores essas perdas dos professores do Movimento Indígena do Alto Rio Negro, amigos dos Baniwas. Diziam eles... pode ir, Braulina, logo a senhora volta, dizia Higino, quando contei da minha escolha de estudar. Lembrarei como o senhor era charmoso e suas poses para foto. (Baniwa, junho de 2020)

Notamos um povo construído comunitariamente pelo poder da confiança mútua em lideranças nativas, que hoje segue em plena desconfiança com o Estado. Para Spinoza (1677/2013), essa desconfiança surge da tristeza oriunda de uma coisa passada ou futura, de cuja realização se tem dúvida. Essa desconfiança/medo também esta ligada à falta de segurança, uma emoção constante em suas vidas, pois guardam memórias de cada um dos ataques e mortes promovidos pela gente branca, tanto por armas como por doenças.

No caso das sociedades nativas sul-americanas, também notamos saudades e nostalgias correlacionadas a memórias dolorosas sobre lideranças étnicas que lutaram por seus direitos contra a gente branca e morreram recentemente, cruelmente, sem assistência, por causa do novo coronavírus. 
ao final da tarde de 17 de junho de 2020, com a voz rouca, num misto de tristeza e desespero, Juventino Kaxuyana anunciava em um grupo do WhatsApp que seu irmão Honório não estava mais entre nós, que acabava de partir... todos os filhos e as filhas de Juventino Matxwaya Kaxuyana se entristecem. Era liderança de grande prestígio no segundo quarto do século XX, na região do rio Katxuru (afluente do rio Trombetas), que inclusive define o nome e a identidade dos Katxuyana, ou Kazuyana, como ficaram mais conhecidos, enquanto yana (gente) do katxuru. (Amanakawa Kahyana, junho de 2020, [mídias sociais])

O corpo humano, assim como o corpo político, é um organismo composto de outros organismos, por isso, ambos, enquanto estrutura física pulsante, buscam perseverar em sua existência, o que só é possível no encontro com outros corpos, na coexistência compreendida como necessária para que o eu (self) possa ser/existir em comum. "O corpo, além de imaginante, é memorioso, fazendo com que a alma tome como presente imagens do que está ausente e com elas represente o tempo, isto é, sequências associativas e generalizadoras de imagens instantâneas gravadas em nossa carne” (Chauí, 1995, p. 62).

Para indígenas, no contexto da pandemia e da necessidade de isolamento, esse bom encontro parece nunca ter ocorrido. O corpo individual e o corpo político não partilham um útil-comum e nem o formam com o corpo do Estado. Pelo contrário. Indígenas denominam a relação com o Estado de "tacape do diabo". A expressão miraçãga anhãga (tacape do diabo) representa, dentro do tronco Tupi, em contexto de terminologia Sateré-Mawél AM e para demais etnias falantes de variantes do Tupi, representação que reclama daquilo que Estado e mercado significam a povos indígenas (Paiva, Junqueira, Albuquerque, \& Ferreira, 2019).

É um modo de externar o quão inconsequente tem sido a gente branca ante os povos originários, mediante o uso da mercadoria e do capital como aliados em massacres simbólicos e físicos. A complexidade intrínseca do dito miraçãga anhãga dá conta do seguinte problema: o "tacape do diabo", quando falado, significa que a etnia está se remetendo a um instrumento de violência contra a sua ancestralidade. Também se diz, pela expressão, do modo de vida da gente branca como um mal encarnado, como uma praga ou um castigo recebido.

O cenário da pandemia entre povos indígenas amazônicos e brasileiros não é consequência vivida apenas no tempo presente, mas também em um tempo passado. Viver o surto global de Covid-19 hoje é, para a natividade, afetar-se novamente por uma história de genocídio já vivida, enquanto povos de primeira nação outrora impactados por uma colonização que ficou marcada em seus corpos memoriosos.

No entanto, repetindo o que foi dito, esse sofrimento histórico não os/as paralisa. Ao contrário. Impulsiona-os/as e os/as mantêm resistindo às paixões tristes, amealhadas nos encontros de seus corpos com o corpo social. Como diria Spinoza (1677/2013), eles/elas promovem o ato em impulso por uma paixão mais forte e contrária. Paixão que, para os povos Sateré-Mawé, em singular no âmago do isolamento territorial, é o sentimento do comum. Próximo ao que Spinoza (1677/2013) denomina de misericórdia, aliada também ao contentamento íntimo.

A trama afetiva do comum, assim, é um sentimento que expande a potência pela afetação do/a outro/a, como signo emocional comum (Vigotski, 2009). Esse sentimento do comum é acompanhado do reconhecimento ou gratidão com anciãos e anciãs. Eles/as são conhecedores/as, velhos/as sábios/as, e por isso a gratidão pelo cuidado com todos/as. 
A vulnerabilidade à Covid-19 gera sentimentos diferentes aos experimentados pela gente branca em relação aos/às seus/suas velhos/as. A morte de anciãos e anciãs representa mais do que a morte de uma pessoa querida. Representa o desaparecimento de saberes tradicionais, de memórias que dão segurança ao comum. A morte de velhos e velhas gera sentimento de saudade intimista, de nostalgia, pois é vivida como dor pela perda coletiva do nós. Os/as velhos/as, como são chamados/as normalmente anciãos/ãs, são guardadores/as de narrativas cosmológicas e modos de vida ancestrais. Essas pessoas também se inscrevem como mestres e mestras de funções-ritual, as quais são relacionadas a decisões políticas e orientações étnicas de comportamentos. Exatamente tais indivíduos têm sido vítimas da Covid-19.

Não tínhamos médicos, médicas, enfermeiros, enfermeiras, para cuidar de nossa saúde. Mas estávamos acompanhados no dia a dia por ancestrais, sábios [sic] que faziam suas cerimônias de proteção utilizando o breu branco, que servia para a defumação do ambiente, das pessoas e outros seres de estimação. (Rezende, 2020, p. 125)

Anciãos e anciãs guardam o signo emocional do comum. Sua morte revela não uma saudade que aprisiona ou mantém a mente no passado, como fala Paulo Freire (1984) acerca de uma imobilização emocional do tempo, que cristaliza a vida do lugar ou do objeto e as pessoas alvo da saudade. Essa, sim, seria uma saudade de sofrimento e de falta. No caso de indígenas, a saudade que sentem é sentimento próximo ao que Spinoza (1677/2013) denomina de desiderium. É afeto relacionado a um desejo de desfrutar de uma coisa recordada e ao mesmo tempo refreada pela recordação de outras que excluem a existência da primeira.

O filósofo explica que, por recordar, esforçamo-nos em considerar a lembrança com o mesmo afeto de outrora, portanto a saudade/desiderium para os povos originários, em relação a anciãos e anciãs, está ligada a alegria, pois a recordação do comum denota afetos alegres.

\section{O isolamento e as emergências humanas}

O isolamento para nós, não-indígenas, é uma obrigação para salvar vidas. Porém, tem sido agente estressor e levado a perdas progressivas de energia e sentimentos de exaustão emocional, esgotamento físico e psíquico. Está associado à solidão, à saudade, e concorre para conflitos interpessoais, sentimentos de impotência e ansiedade. Além disso, nos confronta com a fome, a perda de emprego e o medo do futuro.

Para indígenas, o isolamento diante de um perigo não é obrigação. É tradição. Ou seja, é ato ancestral em razão do desejo de cuidado, como fazem no cuidado de si (Albuquerque \& Junqueira, 2017). É prioridade coletiva. No caso dos povos originários, a perseverança na existência da coletividade é marcada por saberes cosmológicos, primordiais, que se contrapõem a forças coloniais autoritárias e repressoras (Kopenawa \& Albert, 2015). Também fortalece laços de união entre membros de parentelas, a partir de mutirões para a preparação do cultivo, das caçadas, de festas e ritos. Em síntese, a trama dos afetos configurados a partir de modos nativos de existência conta com ao menos um afeto dominante: o sentimento de comum, fortalecido pela confiança na sabedoria de ancestrais e no parentesco étnico. 
Mas povos indígenas enfrentam um sofrimento ético-político que vem se reproduzindo há séculos. Só que, mesmo assim, a natividade Sateré-Mawé, com a pandemia, por exemplo, soube demonstrar que esse sofrimento contínuo instaurado entre a etnia, em modelos gerais, não precisa necessariamente se transformar em trauma, ou, em termos spinozistas, não precisa se cristalizar e fixar no ingenium. Por causa de uma paixão forte - teor da vida em coletividade - também inúmeras outras etnias, igualmente aos povos Sateré-Mawé, movimentaram-se na Amazônia brasileira. Em nosso estudo de caso, no entanto, sobre o isolamento territorial na TI Andirá-Marau, notamos que essa paixão potencializou às etnias, incluindo-se o povo do Andirá-Marau, que agissem sobre os afetos e não que padecessem deles.

$\mathrm{O}$ ato de isolamento da nação Sateré-Mawé mostrou que a etnia não agiu em solidariedade por egoísmo ou por ter como guia uma razão instrumental, mas sim porque se conduziu a partir de uma estrutura hierárquica clânica uniforme, que alimentou sua esperança. E cabe agora, à luz de reflexões sobre a trama dos afetos na vivência dos paradoxos do isolamento, perguntar pelas emergências humanas que a pandemia expôs, entendendo emergências humanas como necessidades ético-políticas.

Emergências humanas, para Spinoza (1677/2013), impedem o exercício do direito natural, da potência de perseverar na existência, como a melancolia e a falta de confiança ou segurança no coletivo ou no Estado. As emergências de indígenas diferem radicalmente das emergências reativas de demais periferias, as não-indígenas, sejam urbanas ou não, porque estão vinculadas de maneira histórica com a construção social do povo.

Observando rapidamente lives ou podcasts direcionados a psicólogos/as, filósofos/as, profissionais de saúde etc., a política afetiva recomendada é composta de vieses de solidariedade, empatia, amor, capacidade de reinvenção, resistência, superação, emulação, gratidão, reconhecimento e benevolência. São esses os afetos que mais aparecem. Para o povo Sateré Mawé, esses afetos não se constituem enquanto emergências humanas, uma vez que o cuidado de si equivale naturalmente ao cuidado da coletividade.

O isolamento, juntamente com o sentimento de comum, que pressupõe confiança mútua, não foi apenas medida sanitária para o povo Sateré-Mawé, bem como para demais etnias indígenas amazônicas. Foi, sim, um tipo de sabedoria ancestral de sobrevivência frente a agressões genocidas que sofrem ao longo da história. Portanto, o isolamento não vai se esvanecer pela pandemia ter sido mais bem controlada na Amazônia. Ele vai se fortalecer, porque sustenta a solidariedade nativa, o cuidado efetivo da natureza (Krenak, 2020).

Esse cuidado é parte da cosmologia, como nos ensina Josias Sateré, do clã ut (lagarta) dos Sateré-Mawé. Biólogo e pedagogo pela Universidade do Estado do Amazonas e mestre em Sociedade e Cultura na Amazônia pela Universidade Federal do Amazonas. Para ele, o isolamento foi mais uma ação, entre tantas, históricas, de enfrentamento e resistência. Ação importante, sim, porém que cada vez mais tem se configurado como cotidiana, estratégica, de luta contra o Estado na contemporaneidade.

A quarentena, por adequada e preventiva que seja - e em verdade é a tática mais eficaz contra o vírus -, crava um punhal no peito dos mais vulneráveis, que vivem o dilema da proteção à saúde em face à necessidade de manutenção da vida. Um dilema, em suma, fictício, alimentado pelo Estado, porque este se nega a dialogar e formar uma frente estratégica e multidirecionada de resiliência contra o novo coronavírus em regiões de grande trânsito indígena na Amazônia. $\mathrm{O}$ atual governo tem sido um dos mais inoperantes em termos de sustentabilidade e respeito a minorias desde 1964, na ditadura militar. (Sateré, Os invisíveis moradores da capital mundial do folclore, [no prelo] $)^{7}$ 


\section{Considerações finais: reflexão sobre o papel dos afetos na pós-pandemia}

A pandemia está deixando marcas que permanecerão, inclusive porque respondem às necessidades do neoliberalismo conservador, que vê na quarentena uma oportunidade para "passar a boiada nos avanços democráticos”, para o desmonte da saúde pública, do emprego e de direitos trabalhistas. Para novas formas de eugenia, para o desmatamento e a redução de direitos indígenas em face de interesses mercadológicos, dentre outras questões, por exemplo, relacionadas à educação nacional privatista, como a implantação do ensino a distância (Freire, 1984).

Parcela significativa está ficando mais rica (banqueiros/as, a saber), mas a maioria ficou ainda mais pobre, tendo que optar entre o medo da fome e o medo do vírus, e ainda tendo de trabalhar e sair às ruas. Por outro lado, a pandemia oferece uma chance de aprendizado, por meio da revelação plena das emergências humanas que tal organização político-econômica acarreta, e que, se não forem resolvidas, novas pandemias mais letais poderão surgir e gerar mais problemas. E essas emergências continuarão a ter como base a inclusão perversa mediada pela desigualdade.

Para dar conta do desafio, a ação de um estado democrático e lúcido é fundamental. O Sistema Único de Saúde (SUS), mesmo com problemas de desmonte, mostrou-se imprescindível para a mitigação da Covid-19, em termos de gratuidade e extensão da rede clínica ou de tratamento intensivo. Além de atendimentos hospitalares, têm sido fundamentais as pesquisas e a troca de saberes para entender a peste, suas causas e formas de prevenção, além da busca pela vacina, sem fundamentalismos e interesse eleitoreiros, que atrapalharam a tomada de decisões, confundem e acirram a gravidade do vírus.

A inclusão perversa é historicamente vivida por povos indígenas. No entanto, a pandemia tornou aguda a situação, culminando em uma crise humanitária, tanto de saúde quanto de demais comorbidades vividas em razão da desigualdade social. O sofrimento gerado não é democrático. Varia mediado pela condição econômica e por marcas históricas e cotidianas nos corpos memoriosos.

Concluímos que o sofrimento ético-político de indígenas possui trama diferente de demais sofrimentos. Os afetos nominalmente podem ser idênticos, mas a relação entre eles, as ideias e a ação variam, bem como as causas dos afetos também. Como relação à dupla clássica de afetos do poder autoritário, segundo Spinoza (1677/2013), medo e esperança têm sentidos diferentes para indígenas. A essas sociedades nativas, é um medo histórico, que reconhece no presente as violências do passado, ou seja, é afeto triste que não está somente vinculado às pessoas, mas também à história do povo - em que a morte de um/ uma é também a morte de todos/as que compõem esse coletivo, especialmente dos anciãos e das anciãs.

Se a pandemia ameaça vivências na sociedade capitalista branca, existe ainda toda uma gama de existências comuns de indígenas que está sob ameaça, o que sugere um prisma diferente para o momento, tendo em vista a formação do ingenium de sociedades ameríndias estar pautada na desconfiança com as sociedades de karaiwás e o seu vínculo cosmológico com a terra, que deveria ser um lugar de memórias. "Se o corpo foi, uma vez, simultaneamente afetado pelos dois afetos, e, portanto, também a mente, sempre que, mais tarde, esta última for afetada de um deles, será também afetada do outro" (Spinoza, $1677 / 2013$, p. 14). 
"El miedo, la angustia y el terror: he aquí la base para desvirtuar y desviar cualquier transformación que la voluntad social de los hombres [sic] se proponga en una democracia” (Rozitchenet, 2000, p. 119). Mas também pode se transformar em força nessa direção, quando se torna um útil-comum, capaz de mobilizar um coletivo para se proteger de ameaças ao seu direito natural de perseverar na existência (Spinoza, 1677/2014). Ou a vergonha, como fala Marx:

Não deixa de ser uma revelação, ainda que ao inverso. Trata-se de uma verdade que nos ensina, ao menos, a reconhecer a vacuidade do nosso patriotismo, a degeneração do nosso sistema estatal, e a cobrir nosso rosto de vergonha. O sr. [sic] me olha com um meio sorriso nos lábios e pergunta: "E o que se ganha com isso? Vergonha não leva a nenhuma revolução”. Eu respondo: ... vergonha é um tipo de ira voltada para dentro. E se toda uma nação realmente tivesse vergonha ela seria como um leão que se encolhe para dar o bote. (Marx, 1843/2010, pp. 63-64)

Entre o povo Sateré-Mawé, sentimentos negativos de medo, ódio e falta de confiança não impediram a ação, pois não se tornaram dominantes pelo confronto com outro afeto, mais forte e potente, a alegria do coletivo, que constitui o ingenium para indígenas. A sabedoria instrumental, de aplicação no cotidiano, para a etnia, porém, não parece significar um antagonismo de conhecimento na direção do fundamentalismo, como o que vem ocorrendo no Brasil.

A sociedade Sateré-Mawé busca conhecer ideias adequadas, de uso prático, com parâmetros elencados a partir de saberes cosmopolíticos. Quer tecer seu destino a partir de uma construção histórica, de experiência de enfrentamento à colonização e ao racismo, mas não se presta a enviesar pelo fundamentalismo. Assim, notamos que a pandemia revelou mais uma vez a sabedoria dos povos originários, que ensinam um remédio contra as paixões tristes, sustentadas por poderes autoritários: é o sentimento do comum, a emergência humana trazida pelo coronavírus para o planeta. Mas não só à sociedade SateréMawé que nos reportamos. Entendemos que a questão é bem maior.

É uma sabedoria com a qual Lane queria que a psicologia social dialogasse: "não iríamos conhecer o psiquismo primitivo ou ensinar os índios, mas ao contrário, a partir deles fazer uma autocrítica da civilização e da Psicologia, um confronto com aquilo que a cultura dominante (colonialista e capitalista) reprimiu" (Lane, Coelho, Lima, \& Sawaia, 2005, p. 6).

Lamentavelmente, a sabedoria dos povos das terras baixas da América do Sul é uma sabedoria em risco há pelo menos 520 anos, apesar de pautada no sentimento do comum, a partir do qual cuidar de si é cuidar de outros/as. Essa sabedoria, sublinhamos, representa um risco a organizações sociais totalitárias, que se alimentam de afetos tristes, de desconfiança e individualismo. Estamos falando de uma sabedoria que resiste, mas se nada for feito, desaparecerá. E não por causa do coronavírus, mas por outra comorbidade histórica, a desigualdade social. 


\section{Notas}

1 A variável "desigualdade social” tem sido ponderação associada a altas taxas de espalhamento do SARS-CoV-2 no Brasil (Jacobi, 2020; Sousa et al., 2020; Travassos et. al., 2020).

2 São eles os clãs: Sateré ou ut (lagarta de fogo), waraná (guaraná), awy'ato (onça), hywi (gavião/harpia/águia), akuri (cutia), urit'i (inambu), wi'in e meiru (mosca), monuruku (mundurucu), gap/nhap (caba), myrehu (rolinha), sahú(tatu), awyky/awkuy (guariba), wasa'i (açaí), mujum (mutum), yavu (cujubi), haki'i (morcego), hapiri wato ou pyre'k (rato grande), hunanën (mucura) e mo'i (cobra).

3 Relatório entregue referente ao projeto no 03/06269-0, posteriormente publicado no livro: Sawaia, B., \& Purin, G. T (2018). Silvia Lane- uma obra em movimento. São Paulo: EDUC.

4. Usamos o termo gente branca (karaiwá) em todo o texto para se referenciar à sociedade não indígena, pois esta é a expressão utilizada em praticamente todos os seis troncos etnolinguísticos falados por povos nativos da América do Sul. Há certa discordância na grafia, mas, quanto à semântica, é uniforme o entendimento de que karaiwá se refere à "gente inimiga", "gente branca" (Aripunãguá, 2020).

5 Segundo Laurent Bove (2014), leitor de Spinoza, a emoção mais for te e contrária seria a uma hilaritas coletiva, um exercício pleno e extenso de nossos direitos naturais.

6 A presente pesquisa teve fomento de entidade público-privada.

7 Sateré, J. (2020). Indígenas Sateré-Mawé, os invisíveis moradores da capital mundial do folclore, In B. Sawaia, F. Busarello, J. Berezoschi, \& R. Albuquerque (Orgs.), Expressões da Pandemia - Fase 2 (no prelo). Embu das Artes, SP: Alexa Cultural.

\section{Referências}

Albuquerque, R. \& Junqueira, C. (2017). Brincando de Onça e de Cutia entre os Sateré-Mawé. Manaus: Editora da Universidade Federal do Amazonas.

Albuquerque, R. (2020). Espalhamento da covid-19 em barcos do Amazonas. Nota Técnica - 05/06, 2020. Recuperado de https://www.academia.edu/43282606/ Espalhamento da covid-19 em barcos do Amazonas

Aripunãguá, Yaguarê Yamã (2020). Línguas indígenas. Organizado por Rebeca Martins. Recuperado de http://www.wikiwand.com/en/Indigenous languages of the Americas

Atlas ODS/AM. (2020). Boletim Especial $n^{\circ} 6$ (maio) | ISSN: 2675-0384. Manaus: Editora da Universidade Federal do Amazonas. 
Barreto, J. P. L. (2013). Wai-Mahsã: peixes e humanos. Um ensaio de Antropologia Indígena. Dissertação de Mestrado, Programa de Pós-graduação em Antropologia Social, Universidade Federal do Amazonas, Manaus, AM. Recuperado de https://tede.ufam.edu.br/bitstream/ tede/4629/2/Disserta\%c3\%a7\%c3\%a30\%20-\%20Jo\%c3\%a30\%20Paulo\%20Lima\%20Barreto.pdf

Barreto Bará, S. (2020, 23 de março). Transmutar do Coronavírus em Leite e Espuma de Buiuiu. NEAI - UFAM. Recuperado de https://drive.google.com/file/d/1KeCFDpc6kp1 GKCsMbiqqlzvEMQ TPeay/view

Bove, L. (2014). Da confiança política: construir a hilaritas democrática. In N. Baptiste et al. (Orgs.), Spinoza e as Américas, volume 2 (pp. 215-236). Fortaleza: EdUECE.

Brand, A. (1993). O confinamento e seu impacto sobre os Pãi/Kaiowá. Dissertação de Mestrado, Programa de Pós-Graduação em História, Pontifícia Universidade Católica do Rio Grande do Sul, Porto Alegre, RS.

Chaui, M. S. (1995). Espinosa: uma filosofia da liberdade. São Paulo: Moderna.

Ferrante, L. \& Fearnside, P. M. (2020). Protect Brazil's Indigenous peoples from covid-19. Science, 368(6488), 251. https://doi.org/10.1126/science.abc0073

Ferreira, M. L. (2003). Uma suprema alegria: escritos sobre Espinosa. Coimbra, PORT: Quarteto.

Filgueiras, A. \& Stults-Kolehmainen, M. (2020). Factors linked to changes in mental health outcomes 3 among Brazilians in quarantine due to COVID-19. MedRxiv Preprint, Version posted June 13, https://doi.org/10.1101/2020.05.12.20099374

Freire, P. (1984). Intuição e fantasia para a educação de todos. Lua Nova, 1(3), 30-35. https://www.scielo.br/scielo.php?script $=$ sci $\operatorname{arttext\& pid=S0102-64451984000300009}$

Jacobi, P. R. (2020, 22 de maio). Padrão de disseminação urbana da covid-19 reproduz desigualdades territoriais. Recuperado de http://agencia. fapesp.br/padrao-de-disseminacao -urbana-da-covid-19-reproduz-desigualdades-territoriais/33226/

Lane, S., Coelho, M. H. M., Lima, M. S., \& Sawaia, B. B (2005). A emoção em culturas indígenas - o povo Xavante. In B. B. Sawaia \& G. T. Purin (Orgs.), Silvia Lane: uma obra em movimento. São Paulo: Editora Educ.

Leitão, M. (2020, 25 de março). Dois povos indígenas decidem se refugiar na mata para se proteger do coronavírus no Maranhão. Amazônia: notícia e informação. Recuperado de https://amazonia.org.br/2020/03/dois-povos-indigenas-decidem-se-refugiar-na-mata-para-se-proteger-do-coronavirus-no-maranhao/

Kopenawa, D. \& Albert, B. (2015). A queda do céu: palavras de um xamã yanomami (1 ${ }^{\mathrm{a}}$ ed.). São Paulo: Companhia das Letras.

Krenak, A. (2020). O amanhã não está à venda. São Paulo: Companhia das Letras, 2020.

Marx, K. (1843/2010). Sobre a Questão Judaica. São Paulo: Editora Boitempo. Original publicado em 1843.

Amazonas atinge $96 \%$ de ocupação em leitos de UTI da rede pública de saúde, diz Susam. (2020, 23 de abril). Globo, G1 AM. Recuperado de https://g1.globo.com/am/amazonas/noticia/2020/04/23/amazonas-atinge-96percent-de-ocupacao-em-leitos-de-uti-da-rede-publica-de-saude-diz-susam.ghtml

Paiva, E., Junqueira, C., Albuquerque, R., \& Ferreira, G. (2019). O Tacape do Diabo e Outros Instrumentos de Predação. Manaus; São Paulo: Editora da Universidade Federal do Amazonas (Edua); Alexa Cultural. 
Pessanha, P. H. C. (2020). Trajetórias militantes: dramas históricos e psicossociais. Tese de Doutorado, Programa de Pós-graduação em Psicologia Social, Pontifícia Universidade Católica de São Paulo, São Paulo.

Pino, A. (2006). A produção imaginária e a formação do sentido estético. Reflexões úteis para uma educação humana. Pro-posições, 17(50), 47-69.

Reger, M., Stanley, I., \& Joiner, T. (2020). Suicide Mortality and Coronavirus Disease 2019 A Perfect Storm? JAMA Psychiatry. Published online April 10, 2020. https://doi:10.1001/jamapsychiatry.2020.1060

Rezende, J. T. (2020). Coronavírus me faz lembrar! In B. Sawaia, F. Busarello, J. Berezoschi, $\&$ R. Albuquerque (Orgs.), Expressões da Pandemia - Fase 1 (pp. 125-126). Embu das Artes, SP: Alexa Cultural. Recuperado de https://www.academia.edu/43179750/ Express\%C3\%B5es da Pandemia - Fase 1

Roberto, Giordano Bruno Soares (2008). Introdução à história do direito privado e da codificação. Uma análise do novo código civil. Belo Horizonte: Del Rey. Acesso em http://www.pcdlegal. com.br/ constituicaofederal/\#.XxUSZ9JKhdi

Rodrigues, R. A. \& Fearnside, P. M. (2014). Índios Waimiri-Atroari impactados por tutela privada na Amazônia Central. Novos Cadernos NAEA 17(1), 47-73. http://dx.doi.org/10.5801/ ncn.v17i1.1427. ISSN: $1516-6481$

Rozitchenet, L. (2000). Guerra y trauma psicosocial del niño salvadoreño. In I. Martín-Baró (Org.), Psicología social de la guerra: trauma y terapia (pp. 233-249). San Salvador: UCA Editores.

Sawaia, B. B. (2001). O sofrimento ético-político como categoria de análise da dialética exclusão/inclusão. In As artimanhas da exclusão: análise psicossocial e ética da desigualdade (pp. 53-66). Petrópolis, RJ: Vozes.

Sousa, W. C., Gonçalves, D. A., \& Cruz, D. B. (2020). COVID-19: Local/regional inequalities and impacts over critical healthcare infrastructure in Brazil. Ambiente E Sociedade, 23, e0114. Epub July 03, 2020. https://dx.doi.org/10.1590/1809-4422asoc20200114vu2020l3id

Spinoza, B. (1677/2013). Ética (T. Tadeu, trad., $2^{\text {a }}$ ed.). Belo Horizonte: Autêntica. Obra original de 1677 .

Spinoza, B. (1677/2014). Tratado Político. In J. Guinsburg, N. Cunha, \& R. Romano (Orgs.), Obra Completa I: (Breve) tratado e outros escritos (pp. 210- 222). In São Paulo: Perspectiva. Original publicado em 1677.

Tarrant, A. \& Hughes, K. (2020). A reutilização de dados qualitativos é um campo subestimado da inovação e da criação de novos conhecimentos nas ciências sociais. SciELO em Perspectiva (online). Recuperado de https://blog.scielo.org/blog/2020/06/10/a-reutilizacao-de-dados-qualitativos-e-um-campo-subestimado-da-inovacao-e-da-criacao-de-novos-conhecimentos-nas-ciencias-sociais/\#.XyX9dJ5KjIU

Travassos, L. R. F. C., Moreira, R. M. P., \& Cortez, R. S. (2020). The virus, The disease and the inequality. Ambiente $\Xi^{\circ}$ Sociedade, 23, e0111. Epub July 03, 2020. https://dx.doi. org/10.1590/1809-4422asoc20200111vu2020l3id

Universidade Federal do Amazonas - Instituto de Ciências Exatas. (2020). Relatório Técnico: Resposta ao OFÍCIO No 0174/2020-GP/FAPEAM - Curva de Contaminação COVID-19 Estado do Amazonas ( $1^{\text {a }}$ Ed.). Manaus: Autor. Recuperado de http://www.fapeam.am.gov.br/wp-content/uploads/2020/05/RELATORIO COVID19 MANAUS AM UFAM FAPEAM.pdf 
Vigotski, L. S. (1986/2000). Manuscrito de 1929. Educação e Sociedade, 21(71), 21-44.

Vigotski, L. S. (2009). Imaginação e Criação na Infância: ensaio psicológico. São Paulo: Ática.

Williams, S., Armitage, C., Tampe, T., \& Dienes, K. (2020). Public perceptions and experiences of social distancing and social isolation during the COVID-19 pandemic: A UK-based focus group study. MedRxiv Preprint. Recuperado de https://www.medrxiv.org/content/10.1101/2 $\underline{020.04 .10 .20061267 \mathrm{~V} 1}$

\section{BADER BURIHAN SAWAIA \\ https://orcid.org/0000-0003-4490-0855}

Professora Titular da Pontifícia Universidade Católica de São Paulo (PUC/ SP). Coordenadora do Núcleo de Pesquisa Dialética Exclusão/Inclusão Social (NEXIN) e membro do GT/ANPEPP A Psicologia Sócio-Histórica e o contexto brasileiro de desigualdade social, o qual fundou.

Endereço: Rua Monte Alegre, 984. Perdizes. CEP - 05014-901 - São Paulo/SP.

E-mail: bsawaia13@gmail.com

\section{RENAN ALBUQUERQUE \\ https://orcid.org/0000-0002-3923-9938}

Professor Adjunto IV da Faculdade de Informação e Comunicação (FIC) da Universidade Federal do Amazonas (Ufam). Coordenador do Núcleo de Estudos e Pesquisas em Ambientes Amazônicos (NEPAM). Pós doutorando do Programa de Estudos Pós-Graduados em Psicologia Social da PUC/SP.

E-mail: renanalbuquerque@hotmail.com

\section{FLÁVIA ROBERTA BUSARELLO \\ https://orcid.org/0000-0002-3384-9305}

Doutoranda do Programa de Estudos Pós-graduados em Psicologia Social da PUC/SP. Bolsista do CNPq fez doutorado sanduíche com bolsa CAPES/ PDSE na Universidad de Salamanca (USAL).

E-mail: frbusarello@gmail.com 


\begin{tabular}{|c|c|}
\hline Histórico & $\begin{array}{l}\text { Submissão: 30/06/2020 } \\
\text { Revisão: 24/07/2020 } \\
\text { Aceite: 24/07/2020 }\end{array}$ \\
\hline $\begin{array}{l}\text { Contribuição } \\
\text { dos autores }\end{array}$ & $\begin{array}{l}\text { Concepção: B.B.S. } \\
\text { Coleta de dados: R.A. e F.R.B. } \\
\text { Análise de dados: BBS, R.A. e F.R.B. } \\
\text { Elaboração do manuscrito: B.B.S., R.A. e F.R.B. } \\
\text { Revisões críticas de conteúdo intelectual importante: } \\
\text { B.B.S., R.A. e F.R.B. } \\
\text { Aprovação final do manuscrito: B.B.S. e R.A. }\end{array}$ \\
\hline $\begin{array}{l}\text { Consentimento } \\
\text { de uso de imagem }\end{array}$ & Não se aplica \\
\hline $\begin{array}{l}\text { Aprovação, ética } \\
\text { e consentimento }\end{array}$ & $\begin{array}{l}\text { O estudo foi aprovado pela Pontíficia Universidade Católica - PUC/ } \\
\text { SP - através do Edital Pipeq/PUCSP - 2019. As falas utilizadas foram } \\
\text { publicadas de forma livre através do boletim Expressões da Pandemia } \\
\text { publicado pelo NEXIN em parceria com o NEPAM e Quarentena } \\
\text { Amazônicas publicado pelo NEPAM. Também houve depoimentos } \\
\text { coletados através das mídias sociais. }\end{array}$ \\
\hline Financiamento & $\begin{array}{l}\text { O Estudo possuiu financiamento do Edital Pipeq/PUC/SP - 2019. E das } \\
\text { entidades de fomento FAPEAM, CNPq, CAPES e CAPES/PDSE através } \\
\text { da concessão de bolsas. }\end{array}$ \\
\hline
\end{tabular}

